SAND98-0977 • UC-600

Unlimited Release

Printed May 1998

\title{
Double-Blind Evaluation of the DKL LifeGuard Model 2
}

\section{RECEIVED \\ MaY 27 1998 \\ OSTI}

Dale W. Murray, Floyd W. Spencer, Debra D. Spencer

Prepared by

Sandia National Laboratories

Albuquerque, New Mexico 87185 and Livermore, California 94550

Sandia is a multiprogram laboratory operated by Sandia Corporation, a Lockheed Martin Company, for the United States Department of Energy under Contract DE-AC04-94AL85000.

Approved for public release; further dissemination unlimited.

\section{(1) Sandia National Laboratories}

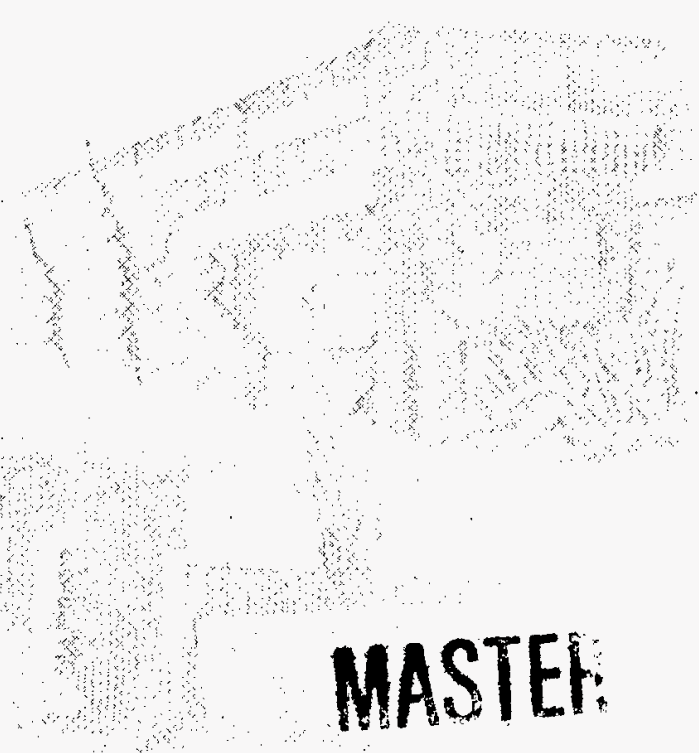


Issued by Sandia National Laboratories, operated for the United States Department of Energy by Sandia Corporation.

NOTICE: This report was prepared as an account of work sponsored by an agency of the United States Government. Neither the United States Government nor any agency thereof, nor any of their employees, nor any of their contractors, subcontractors, or their employees, makes any warranty, express or implied, or assumes any legal liability or responsibility for the accuracy, completeness, or usefulness of any information, apparatus, product, or process disclosed, or represents that its use would not infringe privately owned rights. Reference herein to any specific commercial product, process, or service by trade name, trademark, manufacturer, or otherwise, does not necessarily constitute or imply its endorsement, recommendation, or favoring by the United States Government, any agency thereof, or any of their contractors or subcontractors. The views and opinions expressed herein do not necessarily state or reflect those of the United States Government, any agency thereof, or any of their contractors.

Printed in the United States of America. This report has been reproduced directly from the best available copy.

Available to DOE and DOE contractors from Office of Scientific and Technical Information P.O. Box 62

Oak Ridge, TN 37831

Prices available from (615) 576-8401, FTS 626-8401

Available to the public from

National Technical Information Service

U.S. Department of Commerce

5285 Port Royal Rd

Springfield, VA 22161

NTIS price codes

Printed copy: A03

Microfiche copy: A01

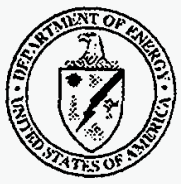


SAND98-0977

Distribution

Unlimited Release

Category UC-600

Printed May 1998

\title{
Double-Blind Evaluation of the DKL LifeGuard Model 2
}

\author{
Dale W. Murray \\ Contraband Detection Technologies Department \\ Floyd W. Spencer \\ Statistics and Human Factors Department \\ Debra D. Spencer \\ Advanced Systems Integration Department \\ Sandia National Laboratories \\ P.O. Box 5800 \\ Albuquerque, NM 87185-0782
}

April 29, 1998

\begin{abstract}
On March 20, 1998, Sandia National Laboratories performed a double-blind test of the DKL LifeGuard human presence detector and tracker. The test was designed to allow the device to search for individuals well within the product's published operational parameters. The Test Operator of the DKL LifeGuard was provided by the manufacturer and was a high-ranking member of DKL management. The test was developed and implemented to verify the performance of the device as specified by the manufacturer. The device failed to meet its published specifications and it performed no better than random chance.
\end{abstract}


This page intentionally left blank. 


\section{Contents}

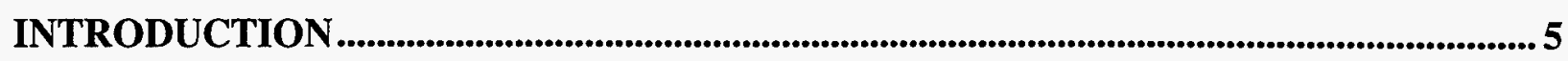

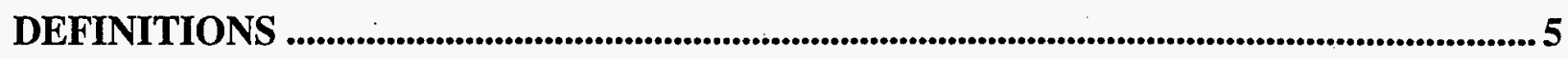

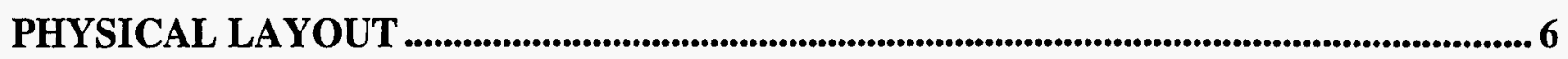

PURPOSE AND PROCEDURE OF THREE TESTS .................................................................... 7

TEST A: BASELINE EVALUATION............................................................................................. 7

Test B: Finding A Single TeSt TaRget Randomly Hidden in One of Five Crates............. 7

TEST C: FINDING TEST TARGETS RANDOMLY HIDDEN IN CRATES .............................................. 8

RESULTS................................................................................................................................................9

GENERAL OBSERVATIONS AND COMMENTS................................................................10

ANALYSIS OF RESULTS................................................................................................................. 10

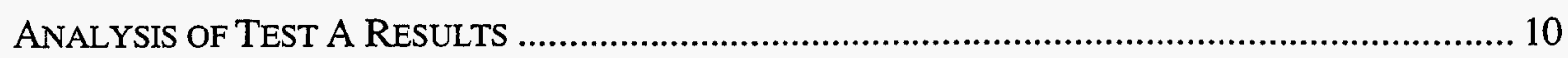

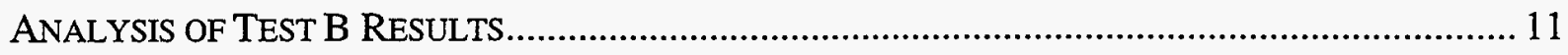

Additional Test B Analysis to Address Comments Made by DKL...................................... 11

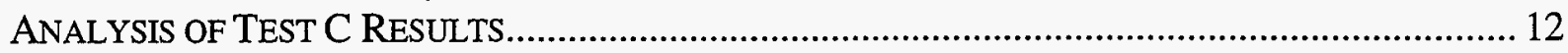

COMPARISON OF RESULTS FROM “TEST” A TO THOSE FROM TEST B ......................................... 12

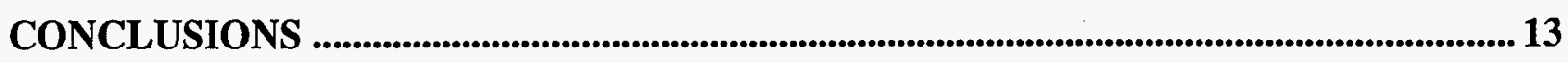

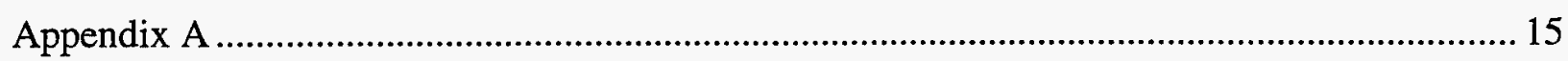

\section{Figures}

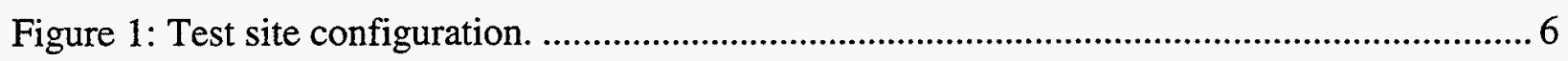

\section{Tables}

Table 1. Test A

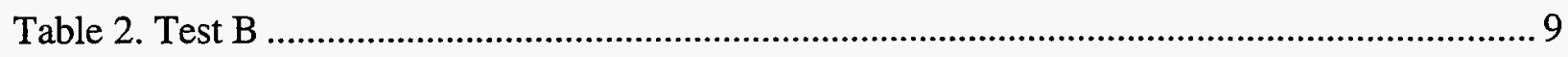

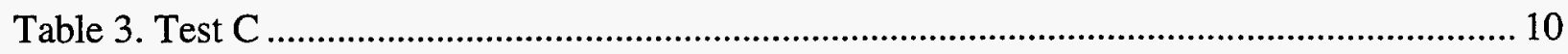

Table 4. Probabilites of Occurrence ............................................................................................. 11 
This page intentionally left blank. 


\section{Introduction}

Sandia National Laboratories in Albuquerque, New Mexico, was asked by the Department of Energy's Office of Safeguards and Security, NN-51, to perform a basic performance evaluation of the DKL LifeGuard (Model 2) human presence detector and tracker from DielectroKinetic Laboratories, LLC (DKL). This device has been advertised by the manufacturer to be capable of detecting living human beings at distances of up to 500 meters through any material. The existence of such a device could be a tremendous help in the areas of search and rescue, law enforcement, and security. Needless to say, the announcement of such a device has gained attention in government circles. The question posed to Sandia was simply: Does this device work?

The guiding principle adopted for this evaluation was to design a test procedure and test layout that would fairly determine whether the device would perform as advertised. Using the product literature, a physical layout was designed with large plastic shipping crates that would allow the operator to use the device well within its advertised capabilities, while preventing any evidence of the Test Target's location to be perceived by the Test Operator. The test was double-blind and random. In other words, the goal was to present the Test Operator with a test that would not be difficult to pass if the device operated as stated and would rely solely on the operation of the device and not rely on the Test Operator having any other information about the location of the Test Target.

\section{Definitions}

Double Blind Evaluation - neither the test participants nor the test administrators know the results or the conditions of the test while testing is in progress (to prevent inadvertent transfer of information between test administrators and test participants).

Test Type - separate test sequences (A, B, and C described below), each consisting of individual trials.

Trial Number - a separate test event within either Test A, B, or C where a Test Operator uses the DKL to determine human presence, or lack thereof, in a set of crates.

Test Operator - individual who uses DKL in trial.

Test Target - individual who hides in one of the crates during a trial.

Actual Crate - crate where Test Target hides during operation of DKL.

Selected Crate - crate indicated by DKL Test Operator to have an individual hidden inside.

Test Set-up Manager - individual who directs Test Targets to hide in specific crates and then determines that no visible clues remain that would indicate which crate is occupied.

Test Operations Manager - individual who supervises the test and recording of test results once the Test Target is hidden in a crate.

Test Recorder - individual who records the test results. 


\section{Physical Layout}

The first parameter defined for the physical layout was the distance between the Test Target and the Test Operator. The product literature specifications for the Model 2 (the model tested) states, "Range: Selectable 0-10 meters or 0-20 meters." This differs somewhat from the range description on page 12 of the Operator's Manual, which states the following: "Most operators can get maximum range in open air past 20 meters using a walk-by and about 30 meters using a scan." The scan method was the method used by the operator during these tests. Using the more conservative 20 meters range, the chosen distance of 50 feet (15.2 meters) is well inside the 20 meters maximum range stated in the product specifications (over 15 feet or $23.8 \%$ inside the maximum range). A shorter distance could have been used but at the risk of the Test Operator seeing or hearing something that might indicate the location of the Test Target.

Next the separation between the test locations was chosen. The product literature specifications for the Model 2 state: “Accuracy: $\pm 5^{\circ} @ 20$ meters." A separation distance of 30 feet $(9.1$ meters) was chosen. The 30 feet separation between the crates with the 50 feet scanning distance results in an angular separation of $\pm 31^{\circ}$, more than six times the stated accuracy.

Some means of visually screening the Test Target from the view of the Test Operator had to be found. Several plastic high-density polyethylene (HDPE) crates were located. These shipping crates provided a visual barrier as well as clear Test Target locations. The fact that the crates were made of plastic seemed to be of no concern because the product literature states, " The LifeGuard can locate and track living humans through walls, barriers, and inside moving or stationary vehicles." Also the specifications state, "Penetrates all forms of camouflaging" and "no known countermeasures.".

Another consideration was to select a location where no other people would be in proximity to the test area, especially in front of the Test Operator as he scanned for the Test Target. For this reason, a remote area on Kirtland Air Force Base was selected. Other factors that made this site attractive were the presence of an instrument trailer that could serve as a base of operation and a small structure (laser shed) behind which Test Targets could hide from view. Figure 1 shows the final configuration of the test site. The $10^{\circ}$ angle shown around crate number 3 is the product literature stated $\pm 5^{\circ}$ accuracy.

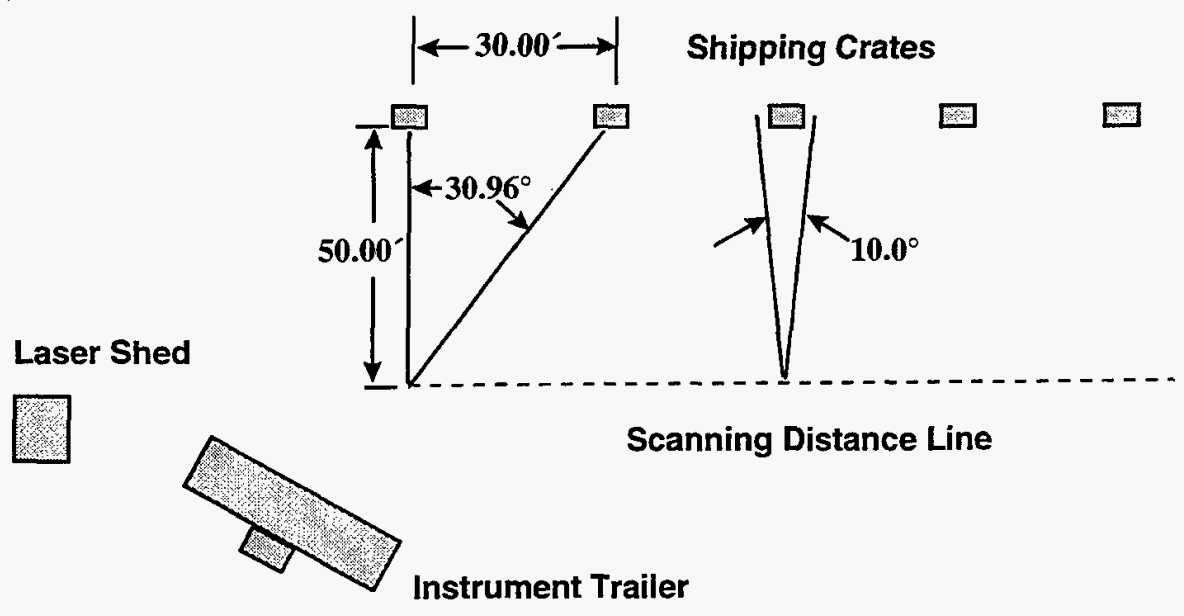

Figure 1: Test site configuration. 


\section{Purpose and Procedure of Three Tests}

\section{Test A: Baseline Evaluation}

- Purpose of test is to let the Test Operator establish that unit is working to his satisfaction under test conditions where one Test Target occupies exactly one known crate per trial.

- Test A results cannot and should not be construed as a true test of unit effectiveness since Test Operator has prior knowledge of actual location.

- Test Operator is allowed as much time as needed to determine the location of the Test Target.

In each trial in Test A, the DKL Test Operator is allowed to view which crate Test Target occupies as trial begins. The crate is chosen at random from Crates 1 - 5 (each crate has equal probability of being chosen, and exactly one crate has a Test Target in it.) Test Set-up Manager uses sealed test schedules randomly generated by an Excel spreadsheet provided to him for this test to direct Test Target as to which crate to occupy. Test Operator then uses DKL LifeGuard to "determine" which crate Test Target is in, even though he already knows. The purpose of this test is to establish that Test Operator believes device is working when he has full knowledge of test set-up. Test Recorder notes which crate Test Target is in and which crate is indicated by the DKL Test Operator after use of the device. Test Recorder uses the form provided to note results. There is no need to try to mask the test set-up for Test A since this is a baseline test. Test Operations Manager sees that test proceeds appropriately.

\section{Test B: Finding a Single Test Target Randomly Hidden in One of Five Crates}

- Purpose of test is to determine how well the Test Operator can use the DKL Lifeguard to differentiate between five crate locations when he knows that exactly one Test Target is present and that the five crates are equally likely to contain the Test Target.

- Test Operator has no known knowledge of actual crate containing hidden Test Target. In each trial in Test B, DKL Test Operator is not allowed to view which crate Test Target occupies at all. Test Set-up Manager is not allowed to see the scanning process or its results.

- Test Operator is allowed as much time as needed to determine the location of the Test Target.

To begin the trial, Test Operations Manager escorts everyone present except Test Target and Test Set-up Manager to instrument trailer. All these individuals go into instrument trailer, including Test Operations Manager.

Test Set-up Manager uses sealed random test schedule provided to him for this test to direct Test Target as to which crate to occupy. When Test Target is placed, Test Set-up Manager checks carefully to see that no indication is present of the set-up. The Test Set-up Manager then knocks on the instrument trailer door, invites all inside to step outside, and he steps inside the instrument trailer and does not observe the outcome of the trial.

Test Operator then uses the DKL device to determine which crate contains hidden Test Target. Test Recorder notes which crate was indicated by the DKL Test Operator, using the form provided to note results. Test Operations Manager sees that test proceeds appropriately and then escorts the same group back to the instrument trailer for the next trial. The Test Set-up Manager leaves the instrument trailer as the others enter, without being informed of the test results and proceeds to set-up the next trial. No one learns the full results until the entire set of testing is completed. 


\section{Test C: Finding Test Targets Randomly Hidden in Crates}

- Purpose of test is to determine how well the Test Operator can use the DKL Lifeguard to determine which crates are occupied by a Test Target when Test Targets are randomly hidden in each crate with probability $1 / 5$. These tests are performed in blocks of five because five crates were available for use. Thus, from zero to five Test Targets could be present for each block of trials, although the expected number present in any given block of trials is one. Since the device is advertised as useful for detecting live bodies in rubble, this is a useful test for considering detection when multiple bodies can be present at different locations. Test Targets who are not deployed are hidden from view.

- Test Operator is allowed as much time as needed to determine the location of the Test Targets.

To begin the trial, Test Operations Manager escorts everyone present except Test Targets and Test Set-up Manager to instrument trailer. All these individuals go into instrument trailer, including Test Operations Manager.

Test Set-up Manger checks the random schedule and directs Test Targets to hide in crates or to hide behind the laser shed. Each crate has a 0.2 probability of having an occupant. When Test Targets are placed, Test Set-up Manager checks carefully to see that no indication is present of the set-up. The Test Set-up Manager then knocks on the instrument trailer door, invites all inside to step outside, and he steps inside the instrument trailer and does not observe the outcome of the trial.

Test Operator then uses the device to determine which crates contain hidden Test Targets. Test Recorder notes which crates were indicated by the DKL Test Operator to contain Test Targets. Test Recorder uses form provided to note results. Test Operations Manager sees that test proceeds appropriately. Test Operations Manager escorts the same group back to the instrument trailer for the next block of trials. The Test Set-up Manager leaves the instrument trailer as the others enter, without being informed of the test results and proceeds to set-up the next trial. No one learns the full results until the entire set of testing is completed. 


\section{Results}

The following tables (Tables 1-3) list the raw data test results:

Table 1. Test A

\begin{tabular}{c|c|c|}
\multicolumn{1}{c}{ Trial } & \multicolumn{1}{c}{ Actual Crate Occupied } & \multicolumn{1}{c}{ Crate Indicated By LifeGuard Test Operator } \\
\cline { 2 - 3 } 1 & 3 & 3 \\
\hline 2 & 3 & 3 \\
3 & 2 & 2 \\
\hline 4 & 1 & 1 \\
\hline 5 & 3 & 3 \\
\hline 6 & 5 & 5 \\
\hline 7 & 3 & 3 \\
\hline 9 & 4 & 4 \\
\hline 10 & 2 & 2 \\
\hline 3 & 3 \\
\hline
\end{tabular}

There were 10 successes in 10 trials. Test Operator took approximately 30 minutes to complete 10 trials in Test $\mathrm{A}$, including set-up time, an average of approximately 3 minutes per sequence of set-up and trial.

\section{Table 2. Test B}

\begin{tabular}{|c|c|c|}
\hline Trial & Actual Crate Occupied & Crate Indicated By LifeGuard Test Operator \\
\hline 1 & 3 & 4 \\
\hline 2 & 4 & 3 \\
\hline 3 & 5 & 5 \\
\hline 4 & 3 & 3 \\
\hline 5 & 5 & 4 \\
\hline 6 & 4 & 5 \\
\hline 7 & 3 & 4 \\
\hline 8 & 2 & 2 \\
\hline 9 & 1 & 4 \\
\hline 10 & 3 & 1 \\
\hline 11 & 2 & 2 \\
\hline 12 & 3 & 4 \\
\hline 13 & 5 & 4 \\
\hline 14 & 4 & 3 \\
\hline 15 & 4 & 2 \\
\hline 16 & 5 & 1 \\
\hline 17 & 3 & 3 \\
\hline 18 & 2 & 3 \\
\hline 19 & 5 & 4 \\
\hline 20 & 3 & 5 \\
\hline 21 & 1 & 3 \\
\hline 22 & 2 & 3 \\
\hline 23 & 5 & 1 \\
\hline 24 & 5 & 4 \\
\hline 25 & 5 & 5 \\
\hline
\end{tabular}

There were 6 successes in 25 trials. The test of 25 trials took approximately 4.5 hours of total setup and test time, and thus an average of 11 minutes per set-up and trial sequence. 
Table 3. Test C

\begin{tabular}{|c|c|c|}
\hline Block & Actual Crates Occupied & $\begin{array}{c}\text { Crates Indicated By LifeGuard Test Operator as } \\
\text { Being Occupied }\end{array}$ \\
\hline 1 & 2 & 1,5 \\
\hline 2 & 3,4 & $2,3,5$ \\
\hline 3 & none & $3,4,5$ \\
\hline
\end{tabular}

Only 15 trials (in three blocks of five trials) were run due to lack of available time. These 15 trials took approximately 36 minutes. There was no time remaining for more trials of Test $\mathrm{C}$ or evaluation of the device using other Test Operators. An average of 12 minutes per sequence of set-up and block of trials (five trials per block) was used.

A random number generator, generating numbers between zero and four, was used for determining which crates were occupied during Test $C$. These random numbers were secretly preassigned to each crate, and then a DKL representative helped determine actual placement of Test Targets by choosing which number would dictate the presence of a Test Target.

\section{General Observations and Comments}

During the process of conducting Test $\mathrm{A}$, the Test Operator located the Test Target in a short period of time (less than one minute) with no ambiguity. There were no indications from the Test Operator that he was having any trouble operating the device or that anything was interfering with the location determination.

During Test B, the Test Operator began to use longer times for the scanning process. As recommended in the Operator's Manual (page 14), the Test Operator used triangulation to "narrow the possible location of an individual or individuals." The Test Operator began to remark that static charge was causing a "residual" signal leading to false indications on crates that had been formerly occupied. He also stated that the "sharp edges" of the crates were distorting the field and were interfering with detection. However, published capabilities include statements such as "Penetrates all forms of camouflaging" and "no known countermeasures."

Following the scoring of the results, the Test Operator also stated that the position of the Test Target (the Test Target had to sit low to the ground due to the low height of the crates) was causing the field to spread and reducing the horizontal accuracy of the device. A thorough search of the product literature revealed no mention of this field spreading effect. One of the observers remarked during this discussion that in rescue operations the person being sought would most likely be in a prone position. DKL responded by saying that in training they told rescue personnel that the device would only be effective to first indicate a living individual was still in a building and second that he/she was in the left or right half of the building.

\section{Analysis of Results}

\section{Analysis of Test A Results}

No analysis is needed. The Test Operator made ten "correct" identifications in ten trials and thereby established and stated that the device worked to his satisfaction under the test conditions. Note that everyone present at these trials would have the same success rate when asked to identify which crate was occupied by the Test Target. 


\section{Analysis of Test $B$ Results}

Test $B$ was a test to see if the Test Operator could correctly identify the crate containing the hidden Test Target using the DKL Lifeguard when he had no prior knowledge of which crate was the correct one. Note that the Test Operator, without even using the DKL Lifeguard would be expected to guess right an average of 5 times out of the 25 trials. In addition, outcomes of guessing right $2,3,4,5,6,7$, and 8 times out the 25 trials would not be unusual results, together occurring approximately $93 \%$ of the time and each individually occurring more than $5 \%$ of the time. For the Test Operator to completely miss or get only 1 correct would be an unusual event, as would for the Test Operator to get 9 or more correct if he were purely guessing. Thus, the 6 out of 25 correct is very consistent with pure guesswork on the part of the DKL Test Operator, and not at all consistent with any significant assistance being provided by the device.

The following table gives the probability that the Test Operator guesses correctly $0-12$ times out of the 25 , assuming no influence from the $\mathrm{DKL}$ on his choice. All other possible correct totals have probability of occurrence very close to zero.

\section{Table 4. Probabilites of Occurrence}

\begin{tabular}{cc}
$\begin{array}{c}\text { Number of Correct } \\
\text { Guesses }\end{array}$ & $\begin{array}{c}\text { Probability of } \\
\text { Occurrence }\end{array}$ \\
\hline 0 & 0.004 \\
1 & 0.024 \\
2 & 0.071 \\
3 & 0.136 \\
4 & 0.187 \\
5 & 0.196 \\
6 & 0.163 \\
7 & 0.111 \\
8 & 0.062 \\
9 & 0.029 \\
10 & 0.012 \\
11 & 0.004 \\
12 & 0.001
\end{tabular}

Additional Test B Analysis to Address Comments Made by DKL

After the test results were revealed at the end of the day, the representatives from DKL expressed the opinion that they should be given some credit for adjacencies (i.e., the Test Operator indicated presence of the Test Target in one of the crates located next to the actual crate). As discussed in the section on physical layout of the test site, DKL states that Model 2 has an accuracy of $\pm 5^{\circ} @ 20$ meters while the crate spacing of the test layout provides over $30^{\circ}$ of angular separation.

Regardless of whether it makes sense to consider adjacencies, the numbers are still consistent with random chance. The Test Operator indicated the correct location 6 out of the 25 trials and the adjacent location 11 out of the 25 trials for a total of 17 out of the 25 . This left a total of 8 trials whose results were neither correct nor adjacent. Given completely random chance and the actual sequence of locations used in placing the Test Target in crates, 17 or more combined hits and adjacencies can be shown to occur with probability 0.092 . Therefore, the results are still consistent with random chance. 


\section{Analysis of Test $C$ Results}

Test $C$ was a sequence of hit-or-miss trials in that the Test Operator was asked to decide whether a Test Target was present or not for each trial. There were 15 independent trials of presence or absence in a crate (probability of actual presence is $1 / 5$ ). The presence or absence of a Test Target in any given crate during a trial of Test $C$ is completely independent of presence or absence of another Test Target in any other crate during the test.

The Test Operator knew that a random process determined the presence or absence of a Test Target for each crate. The process resulted in 3 of the 15 trials having an individual present. The Test Operator indicated the presence of an individual in 8 of the 15 trials. Only 1 of the 8 was coincident with the actual presence of an individual. In the 7 instances of the Test Operator indicating that no individual was present, an individual was actually present in another crate 2 times. This small number of trials resulted in a higher rate of actual human presence in the "no" calls that in the "yes" calls made by the Test Operator - the exact opposite of what should result if the device was effective. In any case, these results are very consistent with expectations from overlaying the following two independent random processes:

- Random placement of an individual with probability $1 / 5$ per trial, and

- Random "guess" of an individual present with probability $8 / 15$ per trial (since the Test Operator indicated presence of an individual ${ }^{8} / 15$ of the time).

The overlay of the two independent processes results in a probability of $36 / 75[1 / 5 * 8 / 15+4 / 5 * 7 / 15$ $\left.={ }^{36} / 75\right]$ for a correct determination (absence or presence) for each trial. The 6 correct determinations ( 1 correct identification of presence and 5 correct identifications of absence) are fewer than the expected number of $7.2(15 * 36 / 75)$. Thus, one concludes that the results of Trial C are consistent with random chance and the DKL device was ineffective.

\section{Comparison of Results From "Test" A to Those from Test B}

In Test $\mathrm{A}$, there were 10 successes in 10 trials. (Note also that "Test" $\mathrm{A}$ took only one half hour.) In Test B, there were 6 successes in 25 trials. (Note that Test B took approximately 4.5 hours.) Comparing the results from "Test" A to those from Test B, we conclude that the only factor contributing to the correct calls of "Test" A was the prior knowledge the Test Operator had of the exact location of the Test Target.

In support of the above statement, we considered the question: "How likely is it that the same probability of success for the DKL Lifeguard unit under evaluation was operative for both Test $A$ and Test B and the disparate results were due to random chance?" A statistical test known as Fisher's Exact Test calculates the probability of getting results as different or even more different than those obtained for the two test phases. For this set of results, that probability is 0.000044 . Thus, the observed difference is so unlikely, occurring 44 times in one million, that one concludes that the probability of detection was not the same in the two test phases A and B. Since the only condition that changed from Test A to Test B was the prior knowledge of the DKL Test Operator and the Test $B$ results were no better than is expected from random chance, we conclude that the positive results of Test A is due solely to the prior knowledge of the DKL Test Operator of which crate was occupied in Test A. 


\section{Conclusions}

Our evaluation of the DKL Lifeguard, although brief, leads us to conclude that the device performs no better than random chance. Although we only had time to evaluate the device with one Test Operator, that Test Operator was from the DKL organization, was selected by the manufacturer to perform the evaluation, and spent considerable time trying to use the device to the best of his ability. Thus, we conclude that no other Test Operator would be able to establish a better performance of the instrument except by chance.

The lack of an available DKL Lifeguard unit to remain in our possession after the day of testing did not permit us to perform a destructive physical evaluation of the DKL Lifeguard for this report. 
This page intentionally left blank. 


\section{Appendix A \\ Discussions of the Physics of Operation}


This page intentionally left blank. 
DKL product literature states: "The LifeGuards' effectiveness is determined primarily by three of the four variables of Pohl's equation for dielectrophoresis force: the irregularity of the nonuniform electric field, the polarizability of the uncharged material, and the volume and shape of the uncharged material, which acts as a kind of antenna. The field generated by the beating human heart is not very intense, but it is very irregular. DKL then uses newly available polarizable materials and fabricates them into a size and shape that maximize the dielectrophoresis force."

Our response: Dielectrophoresis is a real phenomenon that is used in biotechnology devices that separate biological cells in a fluid. These cells are extremely low in mass and the dielectrophoresis force is exerted by a strong electric field that has a high flux density gradient. The process is carried out in a small area between closely spaced electrodes. The net action of the dielectrophoresis force is to move these extremely small masses perhaps as far as a few millimeters. The reason for the high flux density gradient is the close proximity to the electrodes. In the near field of any point source of electrical charge the flux density gradient is high. However, in the far field ( 20 meters from the human heart is certainly far field) the flux density gradient reduces to nearly zero. The idea that an externally weak signal where the flux density gradient is nearly zero could provide sufficient torque to rotate the relatively large mass of the LifeGuard (let alone overcome the friction in the handle bearings) is clearly wrong.

Another section of the published literature states: "Simply put, dielectrophoresis says that when an uncharged but highly polarizable material is placed in an irregular electric field it will point toward the strongest part of the field, much the way a compass needle points toward the strongest part of the earth's irregular magnetic field -- the North Pole. When a compass needle points to the North Pole, it is reacting to the irregular magnetic field, also called a nonuniform magnetic field. One part of a nonuniform field is always stronger than the others, and material without a charge of its own is always pulled toward the strongest part of the field, which physicists call the maximum spatial gradient position."

Our response: The comparison between the earth's magnetic field and the dielectrophoresis effect is a bad analogy. First of all, the compass needle is not responding to the nonuniformness of the earth's magnetic field. If this were the case, compasses would not work at the equator where the earth's magnetic field flux lines are parallel (zero-flux gradient). The compass needle simply aligns itself with the lines of magnetic flux regardless of the flux density gradient. DKL indicated in discussions following the tests that the antenna on the LifeGuard is used to receive the signal and convey that signal through a filter to the dielectric material over a wire. In their literature they also mention that the device is monitoring the electrical signals of 1.2 to 2.0 hertz $(\mathrm{Hz})$ from the human heart. The wavelength of two hertz is 93,150 miles. The 15 -inch antenna used on the LifeGuard is entirely inadequate for receiving signals of that wavelength. Typical antennas used for radio communications are of $1 / 4$ wavelength in length, which for the frequency response needed by the LifeGuard would be $23,287.5$ miles or nearly 3 times the diameter of the earth. In addition, a dipole antenna (the type used by the LifeGuard) is most efficient when perpendicular to the signal flux, which is just the opposite of the case on this device.

These points about the physics of the device support the conclusion of the results of the empirical tests. This device cannot perform any better than random chance. 


\section{Distribution}

(1) Robert J. Walsh, Director

Office of Security Affairs, NN-50

U.S. Department of Energy

Washington, DC 20585

(1) Edward J. McCallum, Director

Office of Safeguards and Security, NN-51

U.S. Department of Energy

Washington, DC 20585

(1) Marshall O. Combs, Director

Policy, Standards, and Analysis Division, NN-512

U.S. Department of Energy

Washington, DC 20585

(1) Glenn Bowser, Program Manager

Protection Program Operations, NN-512.1

U.S. Department of Energy

Washington, DC 20585

(1) Darryl Toms

Protection Program Operations, NN-512.1

U.S. Department of Energy

Washington, DC 20585

(1) Lynne Gebrowsky, Program Manager

Personnel Security Policy, NN-512.2

U.S. Department of Energy

Washington, DC 20585

(1) Larry D. Wilcher, Program Manager

Technical and Operations Security, NN-512.3

U.S. Department of Energy

Washington, DC 20585

(1) David W. Crawford, Program Manager

Materials Control and Accountability, NN-512.4

U.S. Department of Energy

Washington, DC 20585

(1) Brooks Todd, Director

Field Operations Division, NN-513

U.S. Department of Energy

Washington, DC 20585

(1) Richard Levernier, Program Manager

Assessment and Integration, NN-513.1

U.S. Department of Energy

Washington, DC 20585

(1) Donald J. Solich, Program Manager

Weapons Safeguards and Security Operations, NN-513.2

U.S. Department of Energy

Washington, DC 20585
(1) William J. Desmond, Program Manager

Nonproliferation Support Program, NN-513.5

U.S. Department of Energy

Washington, DC 20585

(1) Donald J. Solich, Program Manager

Production and Energy Safeguards and Security Operations, NN-513.3

U.S. Department of Energy

Washington, DC 20585

(1) G. Dan Smith, Program Manager

(1) Carl A. Pocratsky

Planning and Technology Development, NN-513.4

U.S. Department of Energy

Washington, DC 20585

(1) David A. Jones

Planning and Technology Development, NN-513.4

U.S. Department of Energy

Washington, DC 20585

(1) Don Temple, Director

Headquarters Operations Division, NN-514

U.S. Department of Energy

Washington, DC 20585

(1) Charles C. Coker, Program Manager

Headquarters Physical Protection, NN-514.1

U.S. Department of Energy

Washington, DC 20585

(1) Floyd McCloud, Program Manager

Headquarters Technical and Information Security, NN-514.2

U.S. Department of Energy

Washington, DC 20585

(1) William Hensley, Director

Office of Engineering, Operations, Security, and Transition Support, DP-31

U.S. Department of Energy

Washington, DC 20585

(1) Glen S. Podonsky, Deputy Assistant Secretary

Office of Oversight, EH-2

U.S. Department of Energy

Washington, DC 20585

(1) Vincent J. Moskaitis

Office of Plans, Technology, and

Certification, EH-4.3

U.S. Department of Energy

Washington, DC 20585 
(1) Donald Wentz, Deputy Manager

Safeguards and Security

Lawrence Livermore National Laboratory

PO Box 808

Livermore, CA 94550

(1) R. W. Mortensen, Director

U.S. Department of Energy/OAK

Safeguards and Security Division

1301 Clay Street, Suite 700N

Oakland, CA 94612

(1) William Casey, Actg Director

U.S. Department of Energy/RF

Safeguards and Security Division

PO Box 928

Golden, CO 80402-0928

(1) OASD (C3I / IWSCI)

Attn: COL D. L. Landis, Director, Security Programs

The Pentagon, Room 3C281

Washington, DC 20301-6000

(1) Richard L. Green, Director

U.S. Department of Energy/ID

Safeguards and Security Division

785 DOE Place

-Idaho Falls, ID 83402

(1) Bruce Meppen, Manager

Safeguards and Security

U.S. Department of Energy

Argonne National Laboratory, Idaho Site

PO Box 2528

Idaho Falls, ID 83403-2528

(1) Thomas Gradle, Director

U.S. Department of Energy/CH

Safeguards and Security Division

Argonne, Il 60439

(1) Tony Sanchez

Security Division

U.S. Department of Energy/OR

900 Commerce Road East

New Orleans, LA 70123

(1) D. Rutherford, NIS-7

Los Alamos National Laboratory

Mail Stop: E550

PO Box 1663

Los Alamos, NM 87545
(1) E. Wayne Adams, Director Safeguards and Security Division U.S. Department of Energy/NV

PO Box 98518

Las Vegas, NV 89193-8518

(1) Robert L. Windus, Security Manager

U.S. Department of Energy/BP

PO Box 3621

Portland, OR 97208.

(1) E.C. Sill, Director

U.S. Department of Energy/PNR

Safeguards and Security Division

PO Box 109

West Mifflin, PA 15122

(1) U.S. Department of Energy/SR

Office of Safeguards and Security

Larry Ogletree, Director

PO Box A

Aiken, SC 29802

(1) James Ware, Director

U.S. Department of Energy/OR

Safeguards and Security Division

PO Box 2001

Oak Ridge, TN 37831-8570

(1) U.S. Department of Energy/AAO

Attn: John E. O'Brien, Chief

Safeguards and Security Management

Pantex Plant

PO Box 30030

Amarillo, TX 79120

(1) Pacific Northwest National Laboratory

National Security Directorate

Attn: Barry J. Merrill

PO Box 999

Richland, WA 99352

(1) J. L. Spracklen, Director

U.S. Department of Energy/RL

Safeguards and Security Division

PO Box 550, Mail Stop A6-35

Richland, WA 99352

(1) Gerald Meyers, DOE/HQ

Environmental Safety \& Health, EH-53

U.S. Department of Energy

Washington, DC 20585 
(3) MS0762 Safeguards and Security Library (5807)

$\begin{array}{ll}\text { (1) MS0762 } & \text { D. Spencer (5861) }\end{array}$

$\begin{array}{ll}\text { (1) MS0769 } & \text { D. S. Miyoshi (5800) }\end{array}$

$\begin{array}{ll}\text { (1) MS0768 } & \text { B. J. Steele (5804) }\end{array}$

$\begin{array}{ll}\text { (1) MS0768 } & \text { M. J. Woodruff (5804) }\end{array}$

$\begin{array}{ll}\text { (1) MS0782 } & \text { G. Smith (5848) }\end{array}$

$\begin{array}{ll}\text { (15) } \mathrm{MS0782} & \text { D. Murray (5848) }\end{array}$

$\begin{array}{ll}\text { (1) MS0829 } & \text { F. Spencer (12323) }\end{array}$

(1) MS9018 Central Technical Files (8940-2)

(2) MS0899 Technical Library (4916)

(2) MS0619 Review \& Approval Desk (12690) for DOE/OSTI 


\section{M98005262 \\ |||||||||||||||||||||||||||||||||||||||||||||||||||||||}

Report Number (14)

SAND - $98-0977$

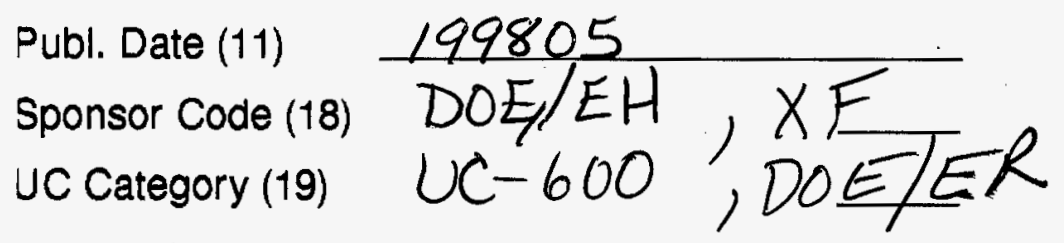

